\title{
Strengthening Public Interest Design Through the Application of Service Learning Pedagogy: A Case Study
}

\author{
SALLIE HAMBRIGHT-BELUE \\ Clemson University
}

\begin{abstract}
Service learning pedagogy provides a compelling tool in the potential transformation of young designers into "Citizen Architects" as the engagement of students with the problems that plague our communities, lie at the very heart of Public Interest Design practice.
\end{abstract}

\section{INTRODUCTION}

This paper details the ongoing efforts within the School of Architecture at Clemson University, with a local, non-profit organization called the FEED \& SEED. The civic interventions and productive community landscapes described are meant to create both compelling urban spaces that are valued and regarded as shared civic assets. More importantly, from our perspective as educators, active student engagement with the community is essential to the pedagogical mission of preparing students for Public Interest Design. In turn, the design studios detailed here understood and positioned the students as engaged designers who are desperately needed in our communities, town halls and professional offices. However, unlike many Public Interest Design projects within academia that rely on the design/build process resulting in a physical product, we directed the students to focus on the process of design and working with the community to understand specific challenges that become evident when studying something as essential as equitable and healthy food access.

\section{SERVICE LEARNING AS A MODEL}

Using service learning pedagogical approaches were useful in these studio projects to achieve the goals of educating and preparing students for Public Interest Design. We were also fortunate that our University was a land-grant institution whose mission calls to "fulfill the covenant between its founder and the people of South Carolina to establish a 'high seminary of learning' through its historical land-grant responsibilities of teaching, research and extended public service." ${ }^{\prime 1}$ The University formally supports work with our state's communities, and has built the foundation for successful collaborations through institutional support and funding.

Many architecture schools, our own included, primarily teach Public Interest Design through design/build courses similar to the example of the Rural Studio at Auburn University. While we acknowledge that design/build projects provide excellent opportunities for students, faculty, and communities, this case study provides a different model when teaching Public Interest Design. We believe that the model we used is more accessible to students and faculty since traditional
MARTIN J. HOLLAND

University of Guelph

design/build courses generally requires specific and technical construction knowledge and skillsets, significant material resources, and large amounts of capital. This traditional design/build model also assumes the architect will be the primary designer of these projects as many Public Interest Design professionals take on that role when they leave academia. However, service learning at our University is based on the principle that students will use their specific knowledge to address community problems. The collaboration with the community is completely integrated into academic course material with the intention of strengthening both:

\begin{abstract}
"Service-Learning at Clemson University is experiential education in which community service experiences complement academic course material. It allows both instructors and students to apply their acquired knowledge and skills in a public setting by performing tasks with or for a community or a specific public organization. These tasks include but are not limited to identifying and analyzing real community needs and developing and implementing solutions to meet those needs. The process is accompanied by reflection activities over the course of the class or project." 2
\end{abstract}

\section{IMPORTANCE OF PROJECT SELECTION}

There are several decisions that must be considered before selecting appropriate service learning projects. It is imperative to choose a project that is emotionally accessible to students, one that clearly shows how social inequalities are reinforced and compounded. Second, it is necessary to be actively engaged in the community, and that the project is sustainable over a significant period of time, often longer than a semester or an academic year. Lastly, it is also crucial to be honest and clear with the community partner in terms of deliverables and outcomes in order to meet expectations of all parties involved.

\section{SOCIAL INEQUITIES ARE COMPOUNDED PROBLEMS}

"Public interest designers advocate for an issue-based approach to problem solving and in doing so are able to confront and resolve more than a single design problem during any given project. Connecting design problems to human issues (social, economic, and environmental) helps establish the value of design to a broader audience and provides designers with a much-needed platform for affirming the value of the work." ${ }^{3}$ 


\section{NEIGHBORHOOD DEMOGRAPHICS}

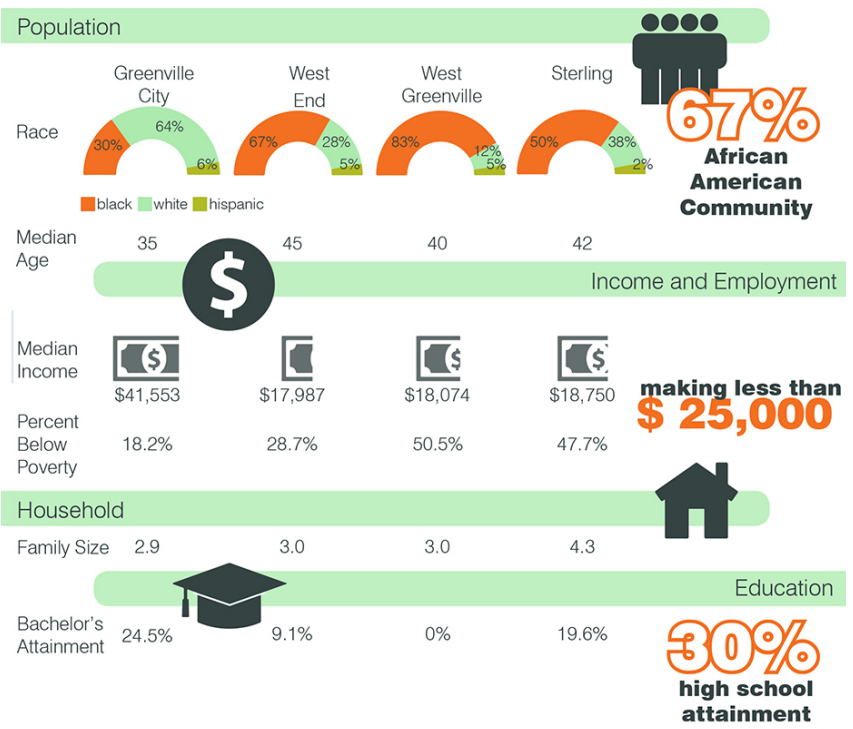

Figure 1: Demographic information for the community

The FEED \& SEED's mandate is to mitigate the social inequities present within the disenfranchised neighborhoods of West Greenville, South Carolina through providing affordable, nutritious, and locally-grown food to these vulnerable areas. This organization and the series of design projects that we coordinated with them provided students a methodology to understand the real social inequities facing disadvantaged neighborhoods. Using a systematic design approach and beginning with considering how food production and delivery operates within the City, was an excellent access point to introduce complex community problems. These kinds of "wicked" and seemingly intractable problems are the kind that Public Interest Designers seek out as the required solutions must be addressed holistically. Additionally, the importance of fresh food is easily accessible to students regardless of their background or frame of reference.

While Greenville has been identified as one of the fastest growing areas in the country, there are many communities that are being disenfranchised and removed from the economic benefits associated with such rapid growth. ${ }^{4}$ This is not an unusual occurrence, and is a common problem found in many cities across the United States. These disenfranchised communities are frequently the home of the most vulnerable and at risk citizens, and in turn, they are the probable location of a potential or existing food desert. The USDA estimates that 23.5 million people, including 6.5 million children, live within food deserts in the United States. ${ }^{5}$ A "food desert" is defined by the United States Department of Agriculture (USDA) as a geographic area whose population lacks the necessary level of income such that they do not have adequate access to fresh and whole foods. ${ }^{6}$
Food deserts are inextricably linked to areas of significant poverty and limited access to fresh and nutritious food. When these two factors mutually coexist, the obesity rate with affected communities usually increases. According to the American Journal of Preventative Medicine, adults who have neighborhood access to stores that sell fresh foods have a $21 \%$ obesity rate, compared with $32-40 \%$ for those living in neighborhoods with no such access. ${ }^{7}$ South Carolina shares the country's food access problem, and according to a recent South Carolina Community Loan Fund study, one million South Carolinians are without adequate access to grocery stores that sell perishable goods, geographically removed from fresh food markets or lack accessibility to affordable and convenient transportation networks to get to such critical places. ${ }^{8}$ These disturbing statistics contribute to an obesity rate of adults in the South Carolina Upstate of $67.9 \%{ }^{9}$

The neighborhoods of West Greenville possess qualitative characteristics that indicate that they are either existing food deserts or are susceptible to become food deserts in the immediate future. These neighborhoods have less than half the median income of the City of Greenville, have a larger number of residents per average household, and have less formal education than their more affluent counterparts. ${ }^{10}$ All of these factors contribute to the likelihood of obesity among the residents, with the absence of a local neighborhood grocery store compounding the problem. While these neighborhoods face challenges, they each possess a strong sense of identity, history, and community. These neighborhoods are $50 \%-83 \%$ African American and are home to the oldest churches and the first African American high school in the area.

\section{SUSTAINED ENGAGEMENT WITH COMMUNITY PARTNER}

Working with the FEED \& SEED offered the students an opportunity to experience a series of design projects that exposed them to social, economic, and environmental issues in a systematic way, indicating how these problems are interdependent and will require novel thinking to reduce their negative impacts. The FEED \& SEED organization is attempting to address the neighborhood's challenges of obesity, general health, and food access from a regional perspective by positioning themselves as a food hub. The USDA defines a food hub as a regional business or organization that actively manages the aggregation, distribution, and marketing of source-identified food products primarily from local and regional producers to strengthen their ability to satisfy wholesale, retail, and institutional demand. In essence, food hubs are a "scaling up" strategy that allows an expanded reach into communities for locally grown and produced food. ${ }^{11}$

The sustained engagement of the FEED \& SEED evolved from faculty's personal involvement with the management of the 


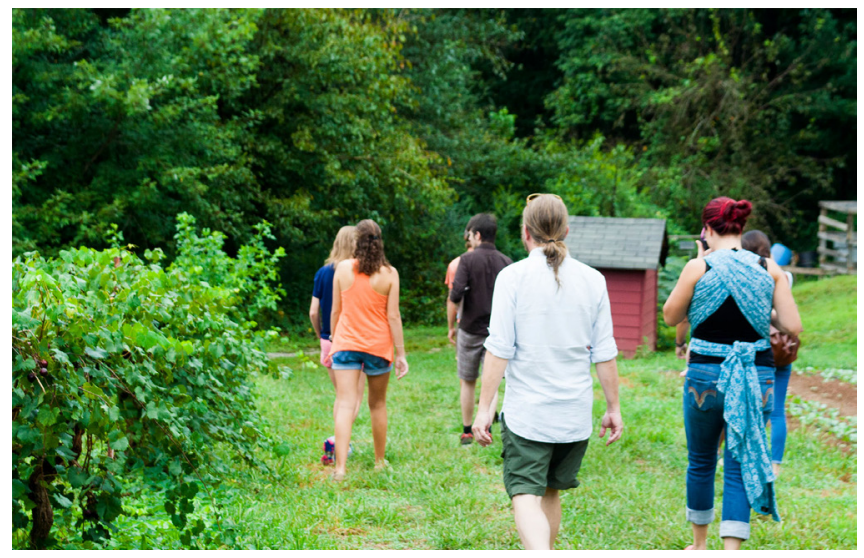

Figure 2: Class field trip to local farm.

non profit, as well as interactions with community members who are activists and advocates for their neighborhoods. This level of commitment allowed the community partner and the University to slowly develop a level of trust and genuine empathy for the investment, commitment and success of the other.

\section{CLARITY OF EXPECTATIONS}

The FEED \& SEED plans to rejuvenate the local food system in a number of ways. The FEED \& SEED intends to provide a large warehouse facility that will meet the wholesale demand for foodstuffs and provide access to individual residents and families in the form of a market. The organization also intends to educate the community at large and the farming community in the advantages and processes of sustainable agriculture. To that end, the warehouse facility will therefore have an educational urban farm in the surrounding landscape. Finally, food distribution locations will be located throughout the region in order to distribute the fresh food items into the at-risk communities and to lessen the effects of existing food deserts.

When the work began on these projects, the FEED \& SEED was in its infancy and did not have a formal process or program developed. Our cooperation with the nonprofit never intended to hand over a professional set of construction drawings, or build any of these studio projects. Rather, the primary goal was to work with the community partner to help them develop their own ideas and understand the scope of the community's problems better so that professional designers could be hired when needed. The secondary goal was to help set up dialogue between the different stakeholders in order to understand the needs and challenges of the multiple parties involved. Finally, studio documents and illustrations created by students to communicate their design ideas to the FEED \& SEED were able to be used to secure future support and funding.

\section{SERVICE LEARNING PEDAGOGICAL OBJECTIVES}

This paper presents a process of introducing Public Interest Design to students. As educators, we found that a strong understanding of service learning, and using service learning classroom objectives was useful in determining and measuring success. While it is our professional responsibility to ensure our students have the expected skillsets required by accrediting agencies, it is our belief, that we have an obligation to educate the design student as an engaged and informed citizen. By focusing on the design process within community service learning projects, we aspire to impart the following characteristics taken from service learning pedagogy: Reflection, Engagement, Empathy, and Citizenship. These characteristics will prepare students for professional engagement with Public Interest Design.

\section{REFLECTION}

The reflective practice embedded within service learning projects inspires students to challenge their own beliefs and mores. This is not a flat footed, blanket promotion of tolerance or diversity, but rather an internal empathic engagement that assists the student to see situations with a wider and more nuanced lens. ${ }^{12}$ This perspective can offer students the realization that the traditional architectural language and renderings, which are often second nature to them, can be viewed as a bewildering and isolating form of communication that reinforces an unintended hierarchy of power. The reassessment of language, terminology, working methods, drawings, illustrations, and models all should be reassessed to effectively communicate to a wider community audience. These tools also need to be used as a way to communicate back to a student in order to reflect on what has been learned about a community.

One student who developed an urban farm project benefited from this kind of reflection. Her project used the idea of kintsugi, a form of Japanese pottery that uses a gold lacquer to hold the collected fragments of broken pottery together. She used kintsugi as a symbolic gesture of repairing the broken food system and restoring the polluted wetland landscape. Her project stemmed from a typical starting point in a landscape architecture studio by focusing on issues of sustainability and restoring a historical wetland but extended into her understanding that the community had dealt with the polluted lands for decades. She reflected on what other struggles the community had been forced to live with and how their health had been negatively impacted. Her project also revealed how harmful and unreflective farming practices are unconsciously transferred from one generation of farmers to the next. Her use of kintsugi as an art form of repairing and restoring a broken object, highlights the necessity of not discarding the majority of farming practices, but rather indicates that the insertion of new principles and best practices can restore a broken system back into a useful, even beautiful entity. In this particular design, restoring the nearby wetland assisted in generating greater biodiversity and provided habitat for local insect populations that would pollinate the produce grown at the FEED \& SEED's urban farm. 


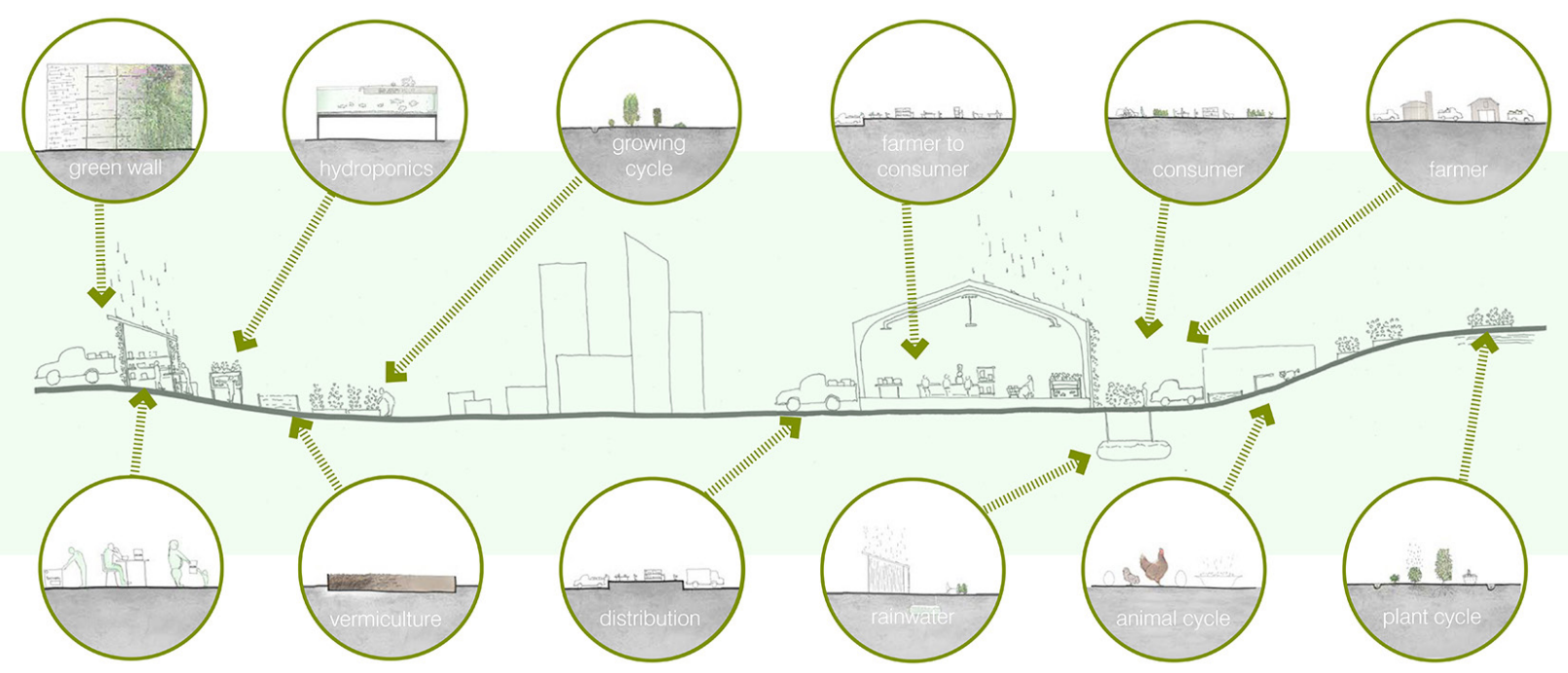

Figure 3: Concept diagram for project focusing on exposure.

\section{ENGAGEMENT}

Projects should inspire students to be engaged with issues that mirror their personal interests, but ensures that those topics are also grounded within the needs of their own local communities. This "grounding" of projects allows students to keep a perspective that is focused on resolution and completion, but communicates that the successes or the failures of a project can have far greater reverberations upon them as students and the community than predicted. This insight provides a sense of purpose and responsibility that is not often encountered within abstract, academic hypothetical projects. As one commentator has observed, "critical service-learning programs encourage students to see themselves as agents of social change and use the experience of service to address and respond to injustice in communities."13 This process of personal engagement with the troublesome issues present within a community also tends to expand a student's sense of empathy for those affected by the problem, and increases the student's awareness of how intersectional and interdependent these issues actually are.

One student group was particularly affected by engagement in the topic of food production and food cycles. The students had no prior experience or understanding of the food system or the challenges facing those in food deserts. Engagement with the topic led them to frame their project around the idea of exposure. They not only wanted to expose the food issues such as growing, economy, quality, and processing but they attempted to also expose the building's environmental effects on the larger community. They found a parallel between the fact that Americans are generally uneducated when it comes to the cycles of food production, and the reinvestment necessary when considering construction, maintenance, and reinvestment cycles of buildings and site infrastructure systems. ${ }^{14}$ This lack of basic understanding of how food is grown, handled, processed, stored, and transported leads to uninformed and poor decisions, which often can lead to poor and unhealthy food choices. Chronic diseases associated with a poor diet account for $75 \%$ of all healthcare costs, which could be redirected to other aspects of prevention and treatment if the basic diet of Americans were changed..$^{15}$ The design team recognized that while poor food choices contributed to poor health, poor building designs and wasteful infrastructure decisions also lead to terrible implications on the environment and economic systems. Their design solution came about by their engagement in the commonalities between the cycles of farming and building construction by using transparent materials and weaving public space throughout the food hub facility and urban farm. No part of the production system was hidden from public view and such visibility encouraged the community to watch and engage with the processes of each as they had done during the project.

\section{EMPATHY}

The role of social empathy for those in a community-based studio cannot be understated, as it extends far beyond mere "do goodism." Rather, the design process provides students an opportunity for open and honest recognition of the needs and limitations of real world communities, as it simultaneously educates them of the larger socio-economic and political forces exemplified by social practices and policy. As noted by Mitchell (2008), “... a critical service-learning approach allows students to become aware of the systematic and institutionalized nature of oppression. The action/reflection dynamic of a critical service-learning pedagogy encourages contemplation of both personal and institutional contributions to social problems and measure that may lead to social change."16 It is that recognition of personal agency that encourages the engagement of citizenship.

One student project focused on the challenges faced by the residents of West Greenville in a way that only occurred once the students developed a deep sense of empathy for the neighborhoods and the challenges they faced. The students began by comparing the cost of food and the capital available that the residents had to spend on food, which opened the student's eyes to immense struggles faced by residents to simply to feed their 


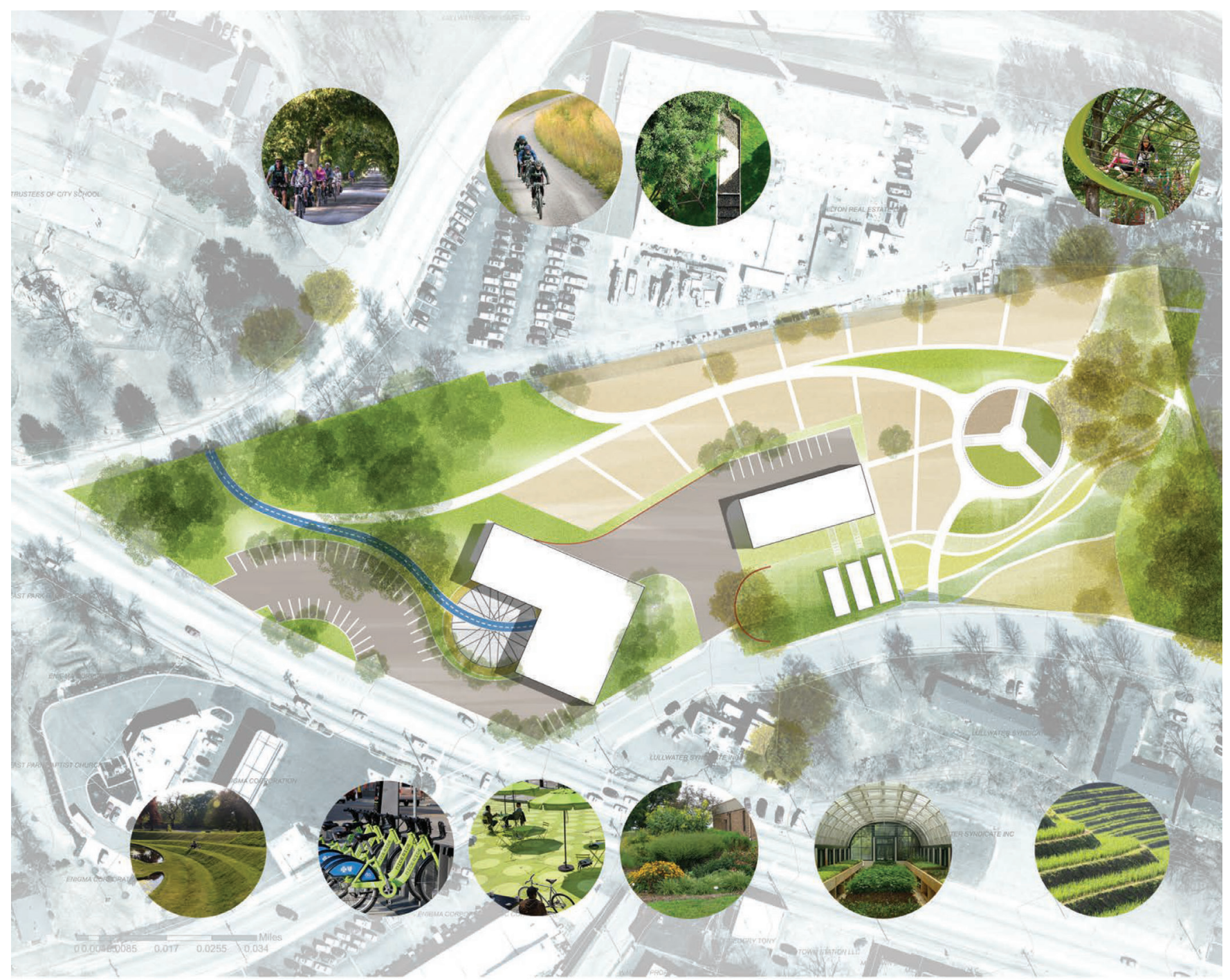

Figure 4: Site plan for project focusing on synergy between bike transportation and food access.

families. This led the students to understand that most challenges are not singular and isolated but rather multiple, interdependent and interconnected. One challenge leading to the inability to purchase fresh food was a lack of basic and affordable transportation. Low cost, reliable, and easily accessible transportation such as bicycling would allow residents to reach places to purchase food, allow residents to access more job opportunities, and encourage a healthy lifestyle.

The student's proposed a synergistic relationship between the food hub, the Greenville bike share program, and the popular Swamp Rabbit Trail recreational corridor. The addition of bike share stops, complete with available bicycles located at the food hub provides the local community with more flexibility and an affordable transportation alternative to the current bus system. ${ }^{17,18}$ In addition, bicycle service encourages increased physical activity, improved access and expanded connectivity to the other parts of the city, enabling community members to take advantage and participate within Greenville's growing economy. The connection with the Swamp Rabbit Trail allowed the community to access Greenville's most valued active recreation asset. Such civic recreational opportunities are scarce in the neighborhoods of West Greenville. The triangulation among increasing resident's access to fresh food, the ability to live an active lifestyle, and improved transportation opportunities addresses health issues found in atrisk communities from a holistic and common sense perspective.

\section{CITIZENSHIP}

Students were challenged to develop meaningful client and community relationships, combined with effective communication and public- process methodologies to ensure that they are accurately representing the desires of the community. This challenges the student designer to express multiple perspectives within a community, and recognize their own voice, agency and expertise within the project. 
It should be noted that these characteristics (reflection, engagement, empathy) are not considered as a mutually exclusive, stepwise procedures, but rather a cyclical process that is constantly evolving and developing. As Eyler (2002) notes, "Effective citizenship should also include an ability to analyze problems and to engage in action. These capabilities have intellectual components such as knowledge, skills and cognitive development. ${ }^{\prime 19}$ It is this return to the reflective comprehension of skill sets and a re-examination of attitudes that are critical to the developmental success of the design student that aims to practice Public Interest Design.

\section{CONCLUSION}

The student projects and processes detailed throughout this paper offer a case study that addresses a range of social justice issues that are both intractable and invaluable within the context of design education. While it is often immensely difficult to challenge some student's perceptions of the people who face multiple social and economic challenges on a daily basis, such exposure provides students the opportunity to become engaged and socially empathic citizens. We encouraged the students to realize that they were not designing for these communities, rather we asked them to design with these communities. This understanding of how Citizen Architects should operate; being more than just the creators of products or places, situates designers as the integral and empathetic center to the decision making processes that constitute neighborhoods, cities, and regions. Designers bring multiple skills, which can expand the discussion and the dialogue concerning economic equity, issues of community building, and ways to create socially equitable spaces. With the continual fragmentation of society, where economic opportunity between the haves and have-nots widens each and every year, we need to be aware, concerned, and engaged regarding the political and economic decisions being made to ensure our work within the urban fabric are not contributing to or accelerating this already great disparity. For us, as educators, and for our students, this is the real value of teaching Public Interest Design - educating future designers to become engaged citizens and knowledgeable about how their decisions and impacts can affect others.

\section{ENDNOTES}

1 Clemson University. n.d. "Mission, Vision and Goals." Accessed September 23, 2107. http://www.clemson.edu/studentaffairs/student-handbook/ clemson-university/.

2 Clemson University. n.d. "Welcome to Service Learning." Accessed September 23, 2017. https://www.clemson.edu/otei/teaching/service-learning/index.html.

3 Abendroth, Lisa and Bryan Bell. 2016. Public Interest Design Practice Guidebook: SEED Methodology, Case Studies, and Critical Issues. New York, NY: Routledge.

4 Christie, Les. April 5, 2012. "10 Fastest Growing US Cities." CNN Money. Accessed, September 23, 2014. http://money.cnn.com/galleries/2012/real_ estate/1204/gallery.US-Cities/9.html.
5 Ver Ploeg, Michele. June 2009. "Access to Affordable and Nutritious Food: Measuring and Understanding Food Deserts and Their Consequences." United States Department of Agriculture. Accessed, February 20, 2016. http://www.ers. usda.gov/media/242675/ap036_1_.pdf

6 United States Department of Agriculture: Economic Research Service, Food Access Research Atlas, Accessed September 4, 2014. http://www.ers.usda.gov/ data-products/food-access-research-atlas/documentation.aspx.

7 Callum-Penso, Lillia. December 2, 2014. “Upstate Making Strides in Tackling Food Deserts." Accessed February 20, 2016. Greenville Online. http://www. greenvilleonline.com/story/news/local/2014/11/28/upstate-makingstrides-tackling-food-deserts/19616021/. The full access to the American Journal of Preventative Medicine can be found at http://www.ajpmonline. org/article/S0749-3797(08)00838-6/fulltext?refuid=S0002-8223(10)018250\&refissn=0002-8223 Accessed, September 27, 2016.

8 South Carolina Food Access Task Force, "Access to Healthy Food in South Carolina: A Report by the South Carolina Food Access Task Force. Fall 2014." Accessed, February 20, 2016. http://www.scfoodaccess.com/ uploads/2/3/0/2/23029886/hffi_statewide_report.pdf.

9 Callum-Penso, Lillia. December 2, 2014. “Upstate Making Strides in Tackling Food Deserts." Greenville Online. Accessed February 20, 2016. http://www. greenvilleonline.com/story/news/local/2014/11/28/upstate-makingstrides-tackling-food-deserts/19616021/. The full access to the American Journal of Preventative Medicine can be found at http://www.ajpmonline. org/article/S0749-3797(08)00838-6/fulltext?refuid=S0002-8223(10)018250\&refissn=0002-8223 Accessed, September 27, 2016.

10 United States Census Bureau, U.S. Department of Commerce. "Quick Facts, Greenville, South Carolina." Accessed, February 25, 2016. https://www.census. gov/quickfacts/table/PST045215/4530850,1731589,45045

11 Park, Scott. December 2014. "Feasibility Study: A Case for an Upstate (SC) Food Hub, Greenville County, December 2014." Accessed February 22, 2016. http:// www.greenvillecounty.org/apps/LongRangePlanning/uploads/Feasibility Study.pdf.

12 Eyler, J. \& Giles., D. E., 1999. Where's the Learning in Service Learning? 29, San Francisco, Jossey-Bass.

13 Mitchell, T. D. (2008). "Traditional vs. Critical Service Learning: Engaging the Literature to Differentiate Two Models." Michigan Journal of Community Service Learning, Spring 2008, 51.

14 Park, Scott. December 2014. "Feasibility Study: A Case for an Upstate (SC) Food Hub, Greenville County, December 2014." Accessed February 22, 2016. http:// www.greenvillecounty.org/apps/LongRangePlanning/uploads/Feasibility_ Study.pdf.

15 "Do You Know Where Your Food Comes From? An Interview with Michael Pollan." The Oprah Winfrey Show. February 1, 2011. Accessed, September 2, 2014. http://www.oprah.com/oprahshow/ Do-You-Know-Where-Your-Food-Comes-From

16 Mitchell, T. D. (2008). “Traditional vs. Critical Service Learning: Engaging the Literature to Differentiate Two Models." Michigan Journal of Community Service Learning, Spring 2008, 54.

17 Greenville B-Cycle. n.d. Upstate Forever and Greenville Health System. Accessed September 27, 2014. https://greenville.bcycle.com/rates

18 GreenLink. n.d. City of Greenville, Accessed September 27, 2014. http://greenvillesc.gov/1204/Schedules

19 Eyler, J. (2002) "Reflection: Linking Service and Learning - Linking Students and Communities." Journal of Social Issues, vol. 58, no. 3, 2002, 520. 